\title{
Protein Engineering for Nicotinamide Coenzyme Specificity in Oxidoreductases: Attempts and Challenges
}

\author{
Andrea M. Chánique ${ }^{1}$ and Loreto P. Parra ${ }^{1,2 *}$ \\ ${ }^{1}$ Department of Chemical and Bioprocesses Engineering, School of Engineering, Pontificia Universidad Católica de Chile, \\ Santiago, Chile, ${ }^{2}$ Schools of Engineering, Medicine and Biological Sciences, Institute for Biological and Medical Engineering, \\ Pontificia Universidad Católica de Chile, Santiago, Chile
}

\section{OPEN ACCESS}

Edited by:

Caroline Emilie Paul, Wageningen University and Research,

Netherlands

Reviewed by:

C. Martin Lawrence, Montana State University, United States

Linda Otten

Delft University of Technology, Netherlands

*Correspondence: Loreto P. Parra Iparrat@uc.cl

Specialty section:

This article was submitted to Microbiotechnology, Ecotoxicology and Bioremediation,

a section of the journal

Frontiers in Microbiology

Received: 01 November 2017

Accepted: 29 January 2018

Published: 14 February 2018

Citation:

Chánique AM and Parra LP (2018)

Protein Engineering for Nicotinamide

Coenzyme Specificity in

Oxidoreductases: Attempts and

Challenges. Front. Microbiol. 9:194.

doi: 10.3389/fmicb.2018.00194
Oxidoreductases are ubiquitous enzymes that catalyze an extensive range of chemical reactions with great specificity, efficiency, and selectivity. Most oxidoreductases are nicotinamide cofactor-dependent enzymes with a strong preference for NADP or NAD. Because these coenzymes differ in stability, bioavailability and costs, the enzyme preference for a specific coenzyme is an important issue for practical applications. Different approaches for the manipulation of coenzyme specificity have been reported, with different degrees of success. Here we present various attempts for the switching of nicotinamide coenzyme preference in oxidoreductases by protein engineering. This review covers 103 enzyme engineering studies from 82 articles and evaluates the accomplishments in terms of coenzyme specificity and catalytic efficiency compared to wild type enzymes of different classes. We analyzed different protein engineering strategies and related them with the degree of success in inverting the cofactor specificity. In general, catalytic activity is compromised when coenzyme specificity is reversed, however when switching from NAD to NADP, better results are obtained. In most of the cases, rational strategies were used, predominantly with loop exchange generating the best results. In general, the tendency of removing acidic residues and incorporating basic residues is the strategy of choice when trying to change specificity from NAD to NADP, and vice versa. Computational strategies and algorithms are also covered as helpful tools to guide protein engineering strategies. This mini review aims to give a general introduction to the topic, giving an overview of tools and information to work in protein engineering for the reversal of coenzyme specificity.

Keywords: oxidoreductases, coenzyme, enzyme engineering, cofactor, NAD(P)H

\section{INTRODUCTION}

Oxidoreductases (EC.1.X.X.X) are a large group of enzymes that catalyze the transfer of electrons from one molecule to another. These enzymes are valuable biocatalysts for industrial uses, since they allow the use of water as solvent and facilitate regio- stereo- and enantioselective conversions. Therefore, oxidoreductases have several applications in the chemical industry, mainly for the production of pharmaceuticals, agrochemicals, biofuels, polymers, amino acids, cosmetics, and nutraceuticals (May and Padgette, 1983; May, 1999; Xu, 2005). 
Oxidoreductases usually need tightly bound cofactors for their catalytic activity, therefore forming part of the enzyme structure permanently as prosthetic groups. Oxidoreductases can also function with external electron donors or acceptors; in this case these cofactors are referred to as coenzymes (Torres Pazmiño et al., 2010) and stoichiometric amounts of them are required for the biotransformation at hand. Among oxidoreductases coenzymes, nicotinamide adenine dinucleotide (NAD) or its phosphorylated equivalent, nicotinamide adenine dinucleotide phosphate (NADP), are the most typical, either in their reduced and oxidized forms. These molecules possess two structural moieties; (i) the nicotinamide, giving the coenzyme its electrochemical function, accepting or donating a hydride group from the C-4 position (Paul et al., 2014) and, (ii) the adenosine, containing the phosphate group (NADP) or the hydroxyl group (NAD) in the 2'-position of the ribose giving the coenzyme its distinction (Knaus et al., 2016). Oxidoreductases are usually specific for one of the coenzymes, those involved in anabolic processes prefer NADP, and the ones participating in catabolic processes prefer NAD (Takase et al., 2014).

Different structural motifs enable the union of the coenzyme and give the specificity for NAD or NADP. Usually, enzymes preferring NADP have larger pockets with positively charged or hydrogen bond donating residues that interact with the phosphate group of the adenine ribose (Pick et al., 2014). NAD preferring enzymes contain negatively charged amino acids that generate repulsion toward NADP and form hydrogen bonds to the $2^{\prime}-\mathrm{OH}$ and $3^{\prime}-\mathrm{OH}$ of the adenine ribose (Petschacher et al., 2014). A recurring structural motif for the binding of coenzymes is the Rossman fold. This nucleotide-binding motif is formed by two $\alpha$-helices and three $\beta$-strands in the alternating pattern $\beta \alpha \beta \alpha \beta$. The pyrophosphate union site is located at the amino terminus of the first $\alpha$-helix, characterized by the conserved sequence GxGxxG in NAD dependent enzymes and GxGxxA in NADP dependent ones (Hanukoglu and Gutfinger, 1989). The specificity to each coenzyme is influenced by the C-terminus of the second $\beta$-strand, where an acidic residue is usually present for NAD preferring enzymes (Carugo and Argos, 1997). Another coenzyme binding fold is the TIM barrel. This conformation can, among others, be observed in the aldo-keto reductase superfamily and is formed by eight $\alpha$-helices and eight $\beta$-strands, alternating and forming a barrel with the $\beta$-strands in the interior and the $\alpha$-helix in the exterior (Solanki et al., 2017).

Switching the coenzyme preference in oxidoreductases is an attractive research area, particularly when these enzymes are used in biocatalysis and metabolic engineering. In some cases, the enzyme is part of a cascade that allows intelligent use of an alternative coenzyme (Gand et al., 2016). The bioavailability of one of the coenzymes or the easiness of their regeneration has been another topic of research (Lerchner et al., 2016). In cell free biotransformations, NAD is usually preferred over NADP due to its much lower price and higher stability (Beier et al., 2016). For some applications it can be desirable that the enzyme uses both coenzymes to increase process efficiency and circumvent metabolic bottlenecks (Pick et al., 2014; Solanki et al., 2016).

In this mini review we focus on the achievements to change the coenzyme preference of oxidoreductases reviewing various coenzyme engineering attempts. We analyzed the different protein engineering strategies and related them with the degree of success in switching the cofactor preference. Computational strategies and algorithms are also covered as helpful complements for the guidance of protein engineering.

\section{ATTEMPTS TO CHANGE THE COENZYME SPECIFICITY IN OXIDOREDUCTASES}

We reviewed 103 enzymes that have been engineered considering their coenzyme specificity and updated the data provided by Cahn et al. (2017) to build a corresponding table (Table 1). To evaluate the degree of success of the reported results, we used three parameters: (i) Coenzyme Specificity Ratio, reflecting the degree of preference of the target coenzyme in the mutated enzyme (Equation 1 when switching from NAD to NADP, and Equation 2 for the opposite direction), (ii) Relative Catalytic Efficiency, which compares the catalytic efficiency of the mutated enzyme with the desired coenzyme and the wild type enzyme using its natural coenzyme (Equation 3 when switching from NAD to NADP, and Equation 4 for the opposite direction), and (iii) Relative Specificity, which compares the coenzyme specificity between the mutated and wildtype enzymes (Equation 5 when switching from NAD to NADP, and Equation 6 for the opposite direction) (Cahn et al., 2017).

$$
\begin{array}{r}
\frac{\left(\frac{k_{c a t}}{K_{m}}\right)_{N A D P}}{\left(\frac{k_{c a t}}{K_{m}}\right)_{N A D}} \\
\frac{\left(\frac{k_{c a t}}{K_{m}}\right)_{N A D}}{\left(\frac{k_{c a t}}{K_{m}}\right)_{N A D P}} \\
\frac{\left(\frac{k_{c a t}}{K_{m}}\right)_{N A D P}^{m u t}}{\left(\frac{k_{c a t}}{K_{m}}\right)_{N A D}^{W T}} \\
\frac{\left(\frac{k_{c a t}}{K_{m}}\right)_{N A D}^{m u t}}{\left(\frac{k_{c a t}}{K_{m}}\right)_{N A D P}^{W T}} \\
\left.\frac{\left(\frac{k_{c a t}}{K_{m}}\right)_{N A D P}}{\left(\frac{k_{c a t}}{K_{m}}\right)_{N A D}}\right)^{m u t} \\
\left.\frac{\left(\frac{k_{c a t}}{K_{m}}\right)_{N A D P}}{\left(\frac{k_{c a t}}{K_{m}}\right)_{N A D}}\right)^{W T} \\
\left(\frac{\left(\frac{k_{c a t}}{K_{m}}\right)_{N A D}}{\left(\frac{k_{c a t}}{K_{m}}\right)_{N A D P}}\right)^{m u t} \\
\left(\frac{\left(\frac{k_{c a t}}{K_{m}}\right)_{N A D}}{\left(\frac{k_{c a t}}{K_{m}}\right)_{N A D P}}\right)^{W T}
\end{array}
$$

We classified the attempts by the EC number, and analyzed the data regarding the degree of accomplishment in switching the cofactor specificity. Different parameters were taken into 


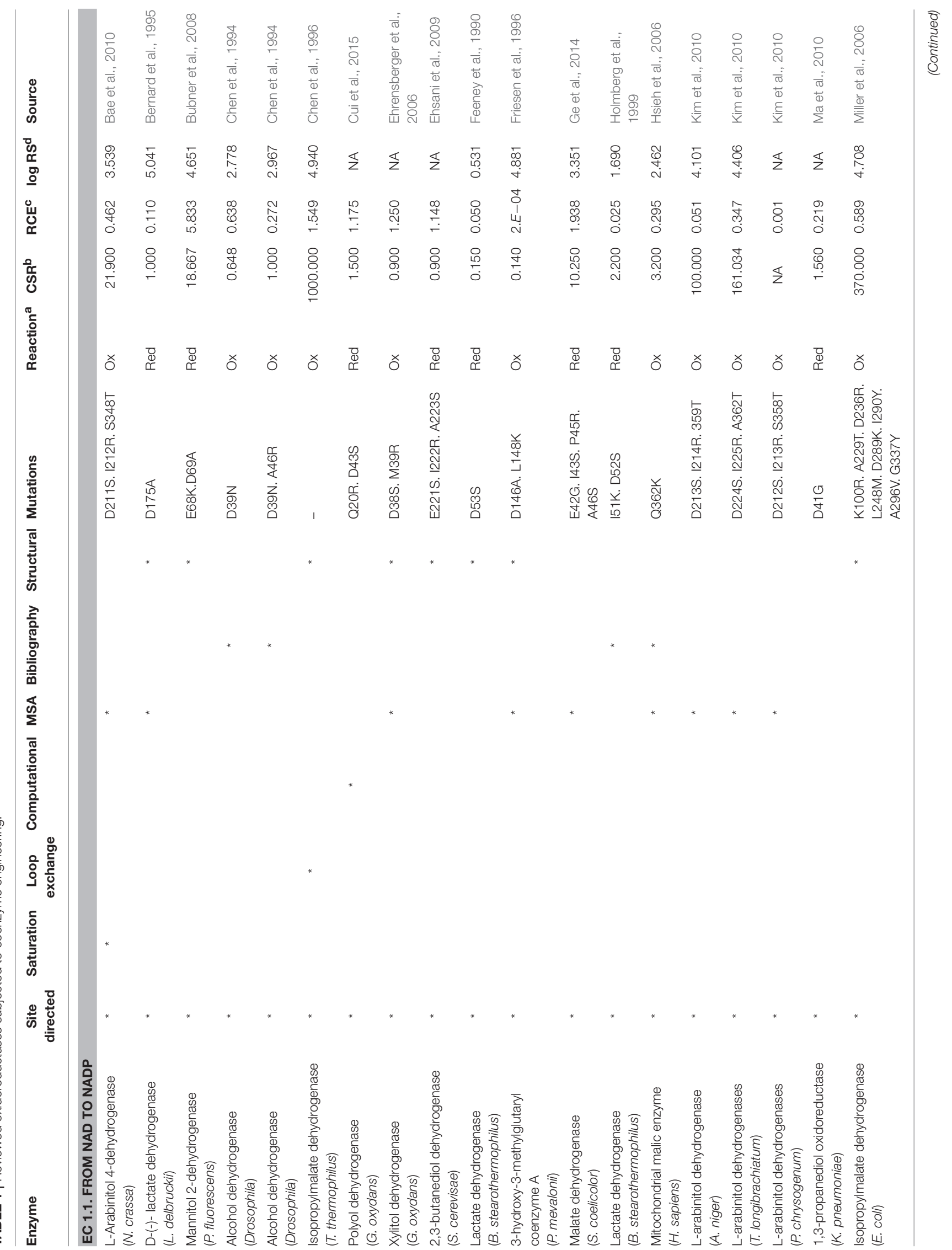




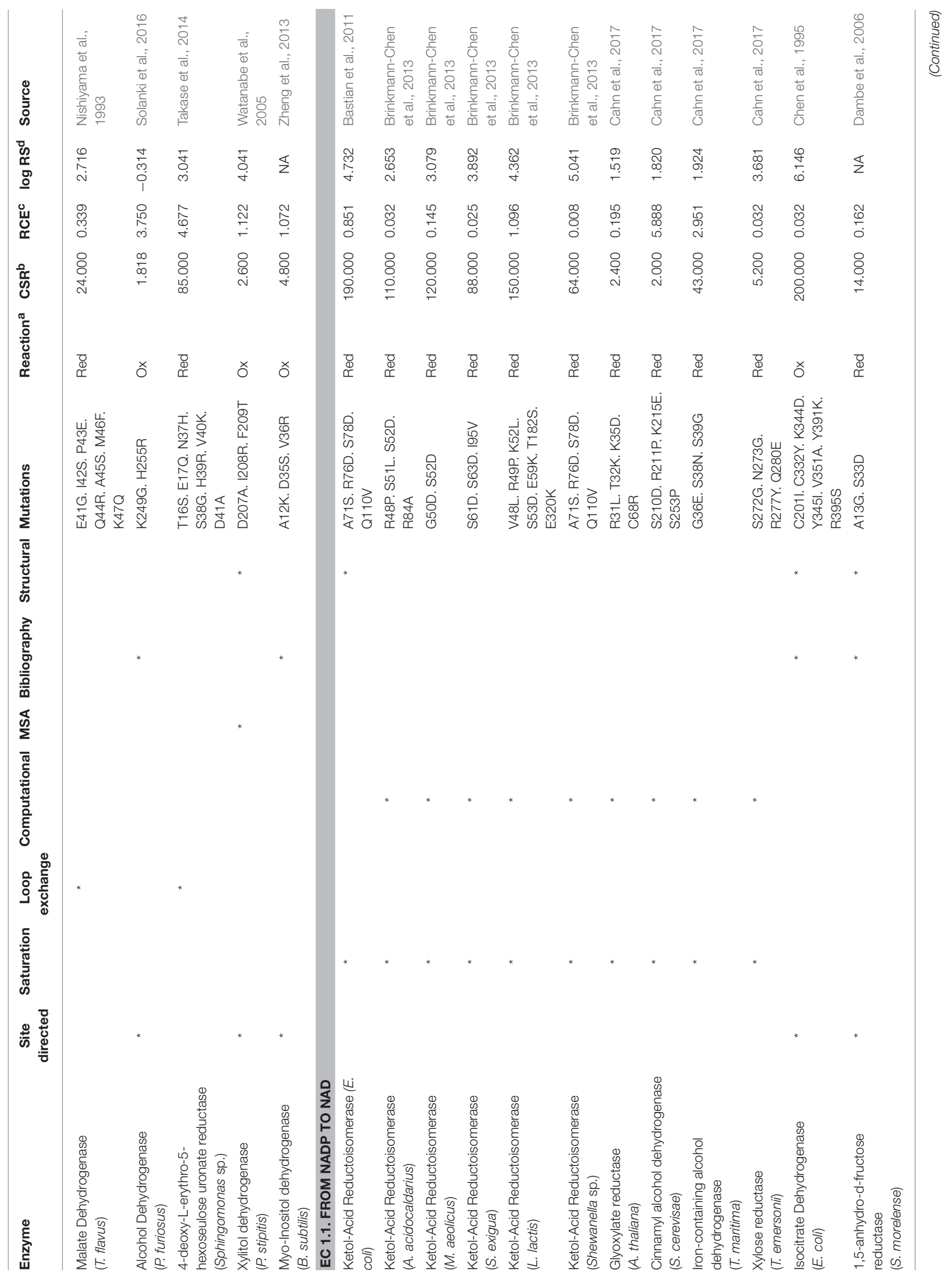




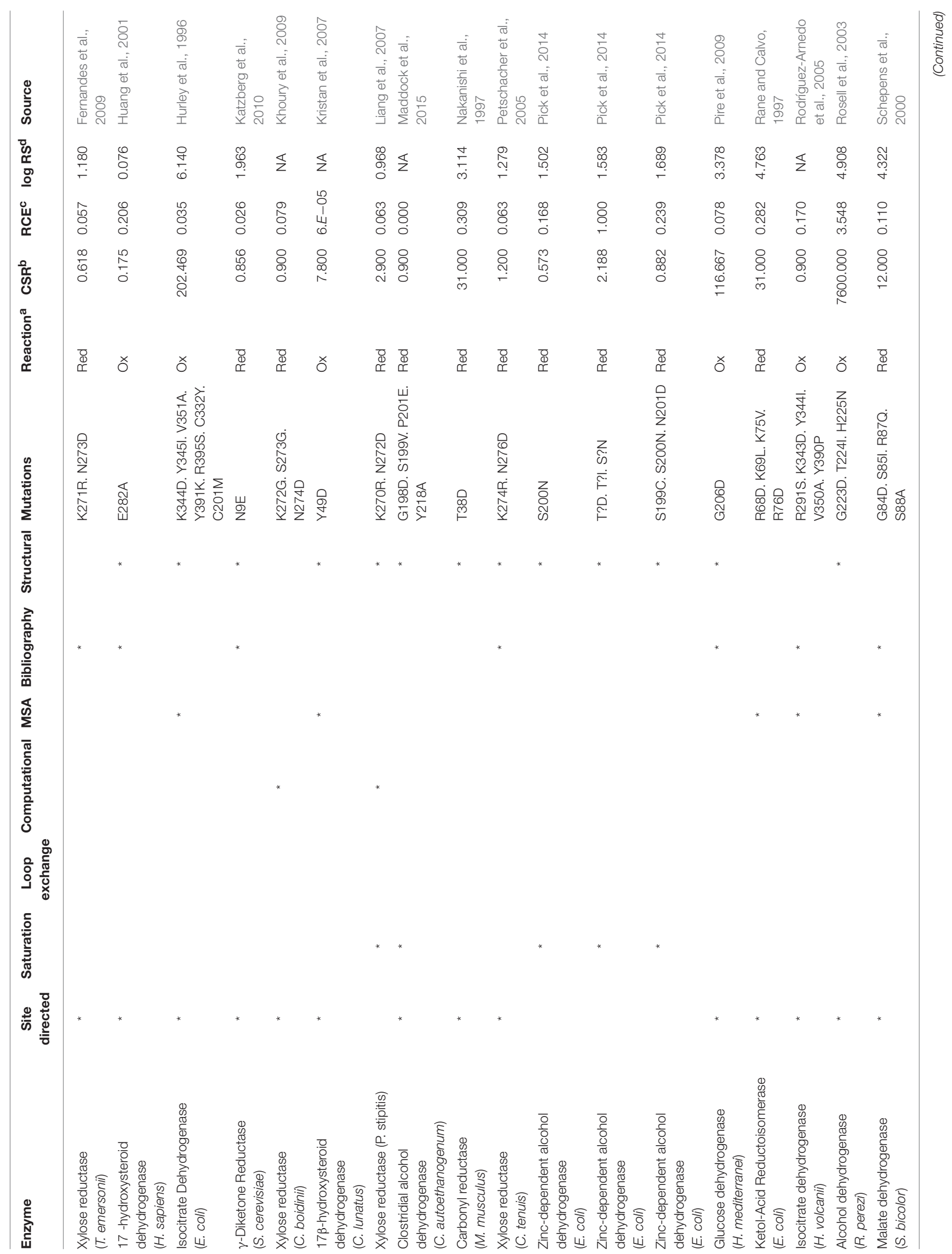




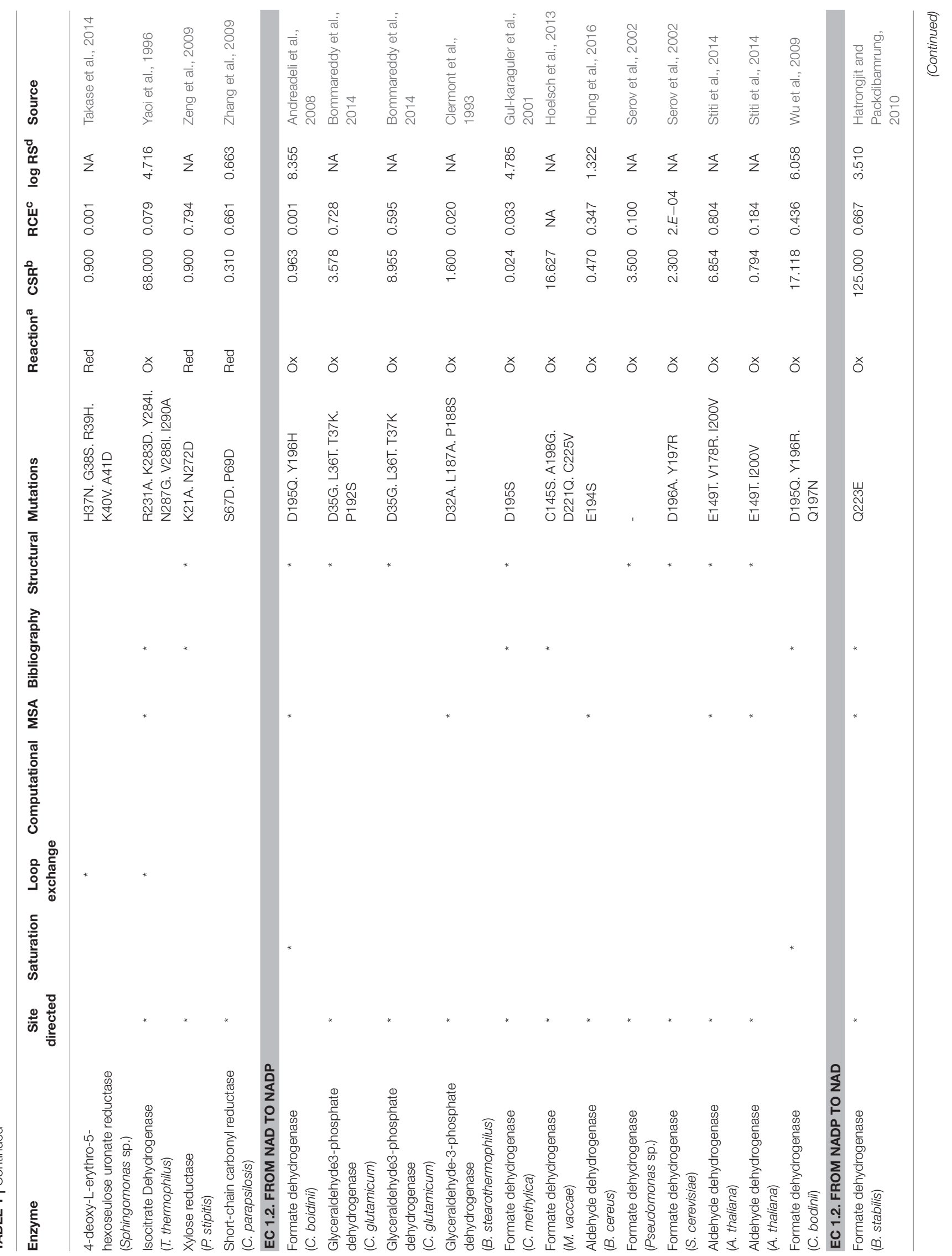




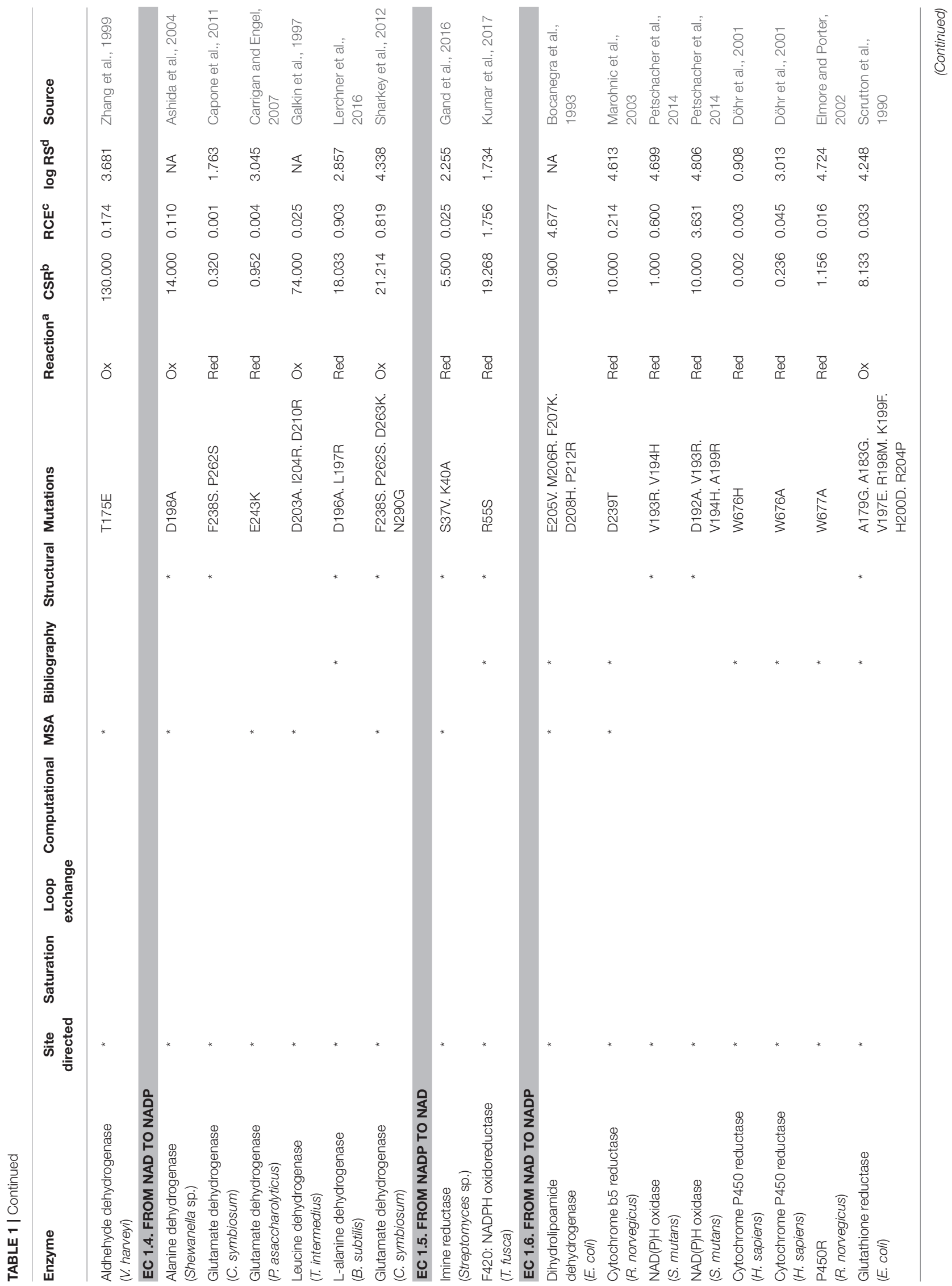




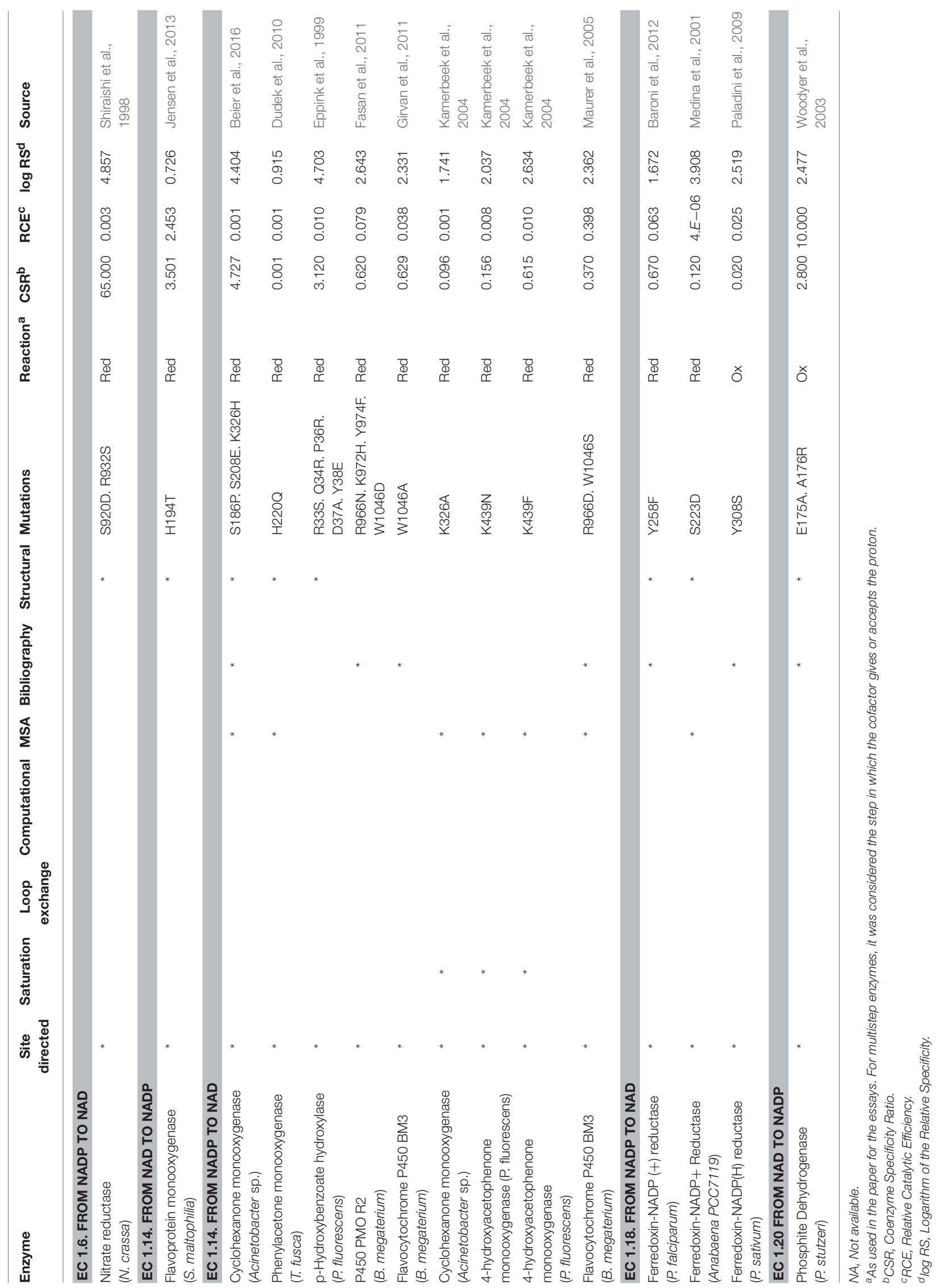


A
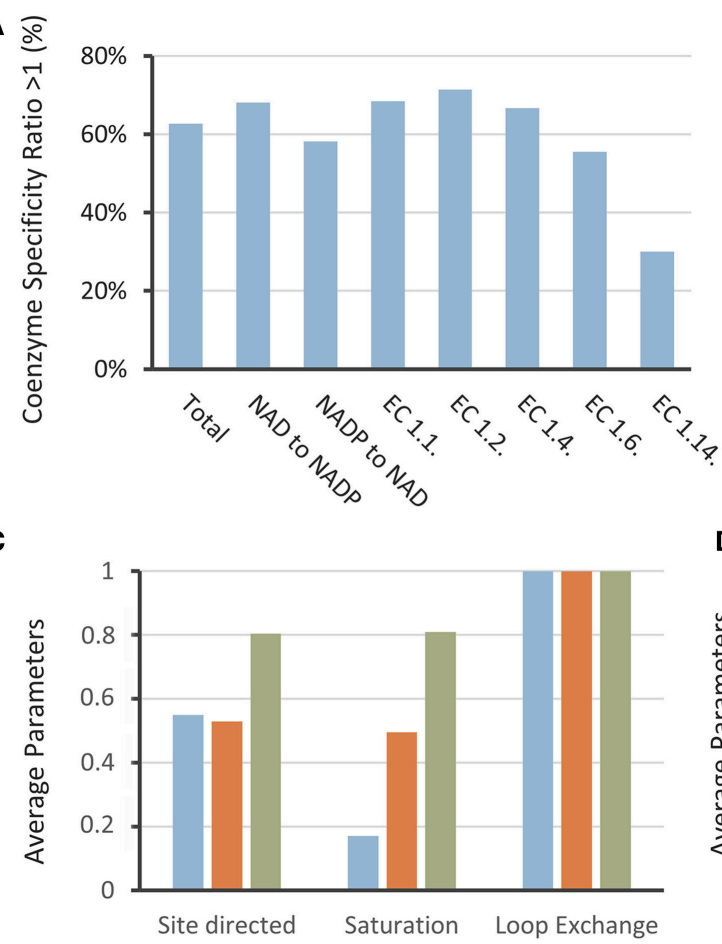

Coenzyme Specificity Ratio

E

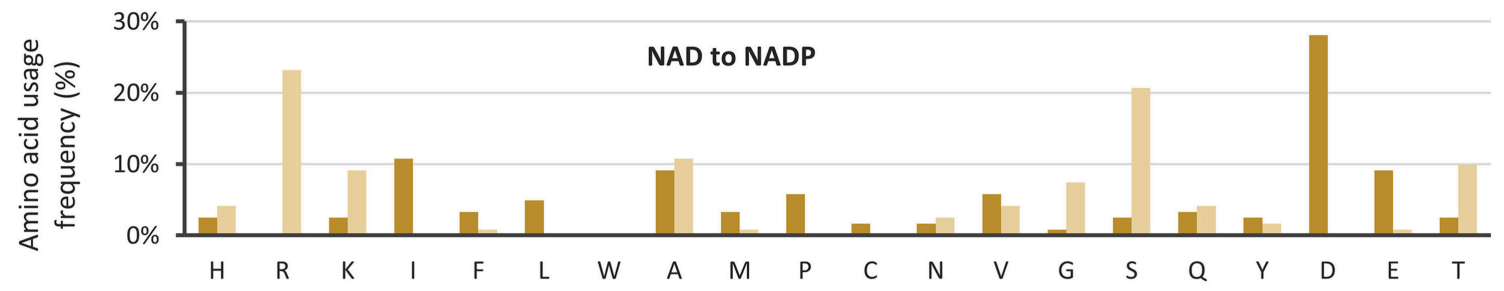

$\mathbf{F}$

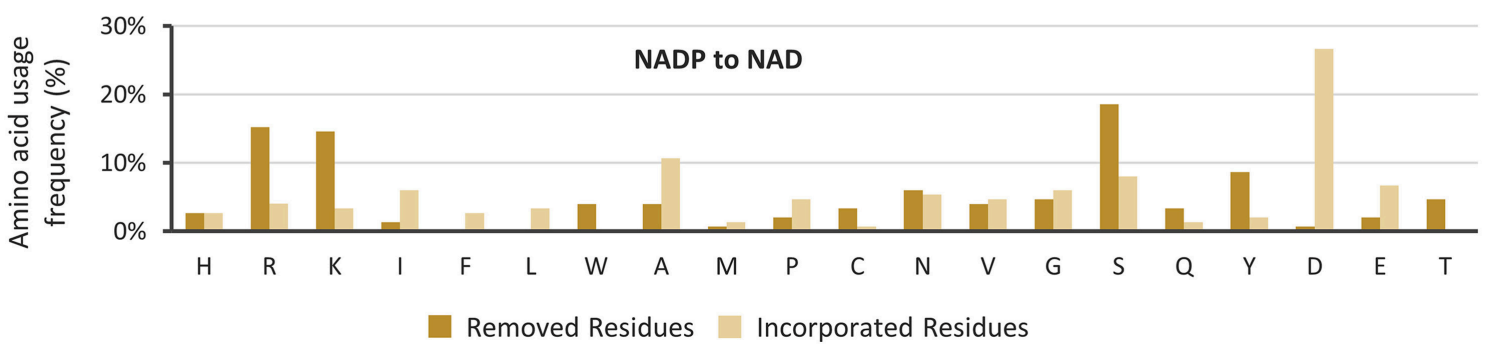

B NAD to NADP

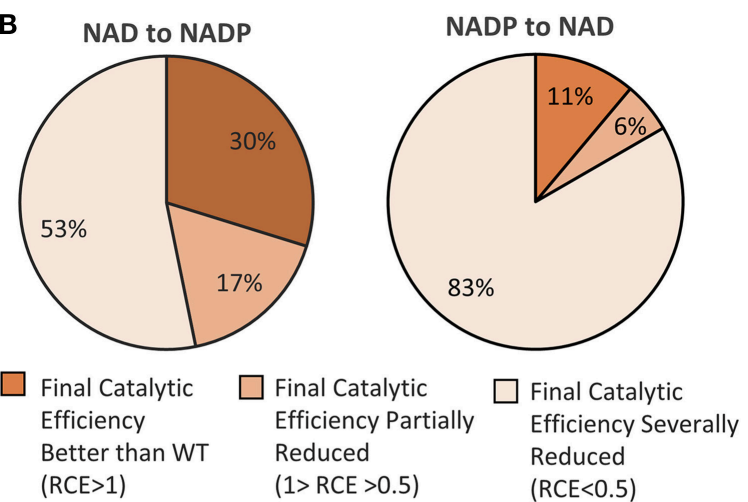

$\square$ Final Catalytic Efficiency Better than WT (RCE $>1$ ) Efficiency Partially Reduced

(1> RCE >0.5)
Final Catalytic
Final Catalytic Efficiency Severally Reduced ( $\mathrm{RCE}<0.5$ )

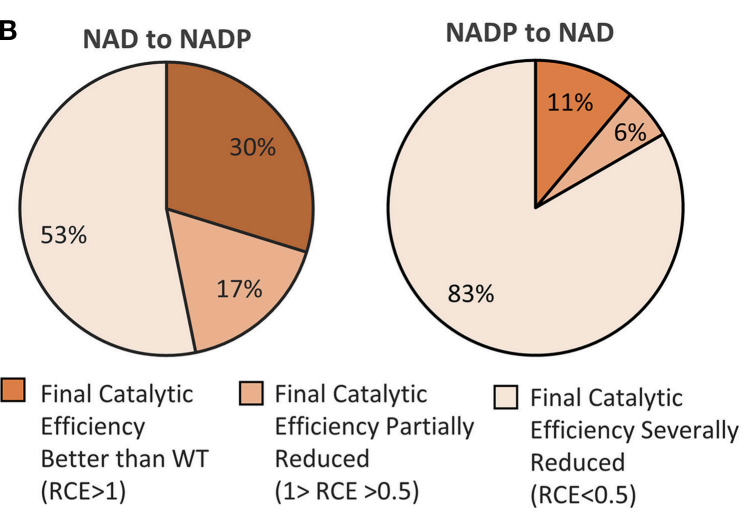

\section{D}

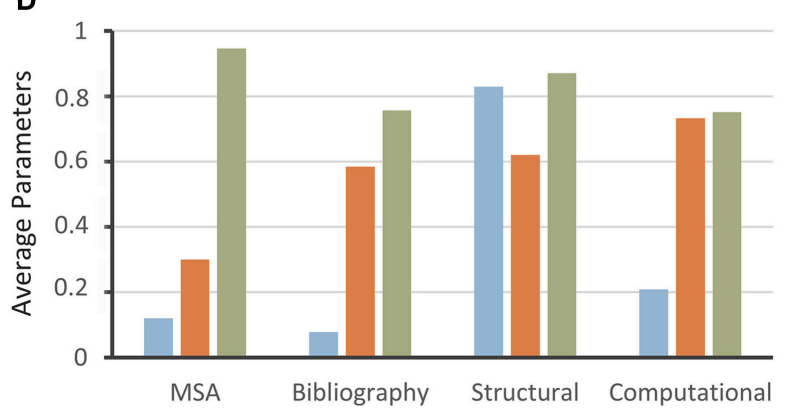

Relative Catalytic Efficiency

Relative Specificity 
satisfactory result (Woodyer et al., 2003; Petschacher et al., 2014).

Most of the studies were performed in enzymes belonging to EC 1.1, with 58 cases considered in this review. The best results were obtained for oxidoreductases of the aforementioned class, together with the ones belonging to EC 1.2. Enzymes classified in EC 1.6 and 1.14 gave poor results. Most enzymes belonging to EC 1.14 are NADP-dependent Baeyer-Villiger monooxigenases, it has been reported that switching the coenzyme preference in these is more challenging, due to the complexity of their electron transfer mechanisms (Beier et al., 2016; Cahn et al., 2017). Recently, Beier et al. (2016) switched the coenzyme preference of a Baeyer-Villiger monooxygenase. The best variant showed higher conversion of cyclohexanone with NADH than using NADPH, however the Coenzyme Specificity Ratio and Relative Catalytic Efficiency were 4.7 and 0.0015 respectively.

Regarding the Relative Catalytic Efficiency, results were separated in three scenarios: (i) Higher than one, indicating that the catalytic efficiency of the mutated enzyme with the desired coenzyme was better than the catalytic efficiency of the wild type enzyme with its natural coenzyme, (ii) Lower than one but higher than 0.5 , indicating that the catalytic efficiency was reduced by less than $50 \%$, and (iii) Lower than 0.5 , which reflects an important reduction of the enzyme functionality. Figure 1B shows the results analyzed by this index when changing from NADP to NAD and vice versa. Most of the attempts resulted in variants with decreased Relative Catalytic Efficiency using the targeted coenzyme. When trying to alter the coenzyme specificity from NAD to NADP, only in $30 \%$ of the cases the catalytic efficiency of the obtained variant with NADP was better than the catalytic efficiency of the wild type enzyme with NAD. When changing from NADP to NAD, only $11 \%$ of the cases showed better catalytic efficiencies, meaning that $89 \%$ of the variants showed a reduced catalytic efficiency when using NAD. Altogether these results show that a change in coenzyme specificity typically leads to a loss of functionality of the enzyme, as has been reported before (Cahn et al., 2017).

The Relative Specificity was also calculated and a $\log$ transformation (base 10) was applied for better analysis of the data (Table 1). Only one of the studies reported an enzyme with values lower than 1 (Solanki et al., 2016). The rest of the values ranged from 1.1 to 8.4 , indicating a favorable change in cofactor preference. The lowest values were obtained when changing from NADP to NAD, averaging a value of 3.0, as compared to NAD to NADP changes which averaged 3.5. Enzymes belonging to EC 1.2 averaged the best value for this parameter (4.6), followed by EC 1.6 (4.0) and EC 1.1 (3.1). Enzymes from EC 1.14 averaged the lowest values (2.5). Although the Relative Specificity gives information regarding the reversal success, it does not indicate information about the absolute degree of cofactor preference or usability of the new enzyme.

The protein engineering approaches utilized were rational or semi-rational, and we grouped them in three categories: site directed mutagenesis, saturation mutagenesis and loop exchange (Figure 1C). Site directed mutagenesis was employed in 82 opportunities, saturation mutagenesis in 20 opportunities, and loop exchange was used in 5 cases and gave best results. In this strategy, a complete region determining cofactor specificity is replaced for a region of another enzyme reported to have the desired cofactor specificity. This approach was used in a DEH reductase (Takase et al., 2014) where two loops were exchanged to switch the specificity from NADH to NADPH, giving excellent results. Despite these good achievements, only a few studies have been reported using loop exchange. One of the limitations of this strategy is to find proper coenzyme-binding loops in a protein with a highly structural identity with the target enzyme.

As we have noticed, rational design is the preferred strategy used for coenzyme engineering; and strategic positions within the cofactor binding site should be identified. We were curious about the criteria used for selection of the residues, and also evaluated the rate of success regarding this parameter (Figure 1D). We classified the approaches in 4 categories: (i) multiple sequence alignments (MSA, 37 cases), (ii) rational transfer of amino acids of previously reported studies (Bibliography, 36 cases), (iii) structural analysis of the coenzyme binding site (Structure, 51 cases), and (iv) computational approaches and use of algorithms (Computational, 12 cases). Some works employed more than one of these approaches, therefore they were considered in each case. As the analysis suggest (Figure 1D), when examining the coenzyme binding site good results were obtained. Therefore, we strongly recommend using this approach for a proper selection of the target positions. MSA and bibliography could also be used as a complement. When computational tools or algorithms were used, their average Relative Catalytic Efficiency was the highest (Figure 1D), therefore we evaluate this approach separately.

We also evaluated the frequencies in amino acids that were removed or incorporated for the engineering of coenzyme specificity. Usually, acidic residues are mutated to switch coenzyme specificity from NAD to NADP (Figure 1E), and are used as a replacement in the opposite case (Figure 1F). In the analyzed studies, when switching the coenzyme specificity from NAD to NADP, $28 \%$ of the residues corresponded to Asp and $9 \%$ to Glu, covering together over one third of the mutations (Figure 1E). When seeking the switch from NADP to NAD, Asp and Glu were added in $34 \%$ of the cases (Figure 1F). The relevance of these residues has been reported in other occasions (Brinkmann-Chen et al., 2014; Pick et al., 2014), and is mainly due to the acidic groups repulsion with the negatively charged phosphate of the NADP (Jensen et al., 2014). On the other hand, amino acids with positive charges stabilize the binding of NADP. Actually, in NADP binding enzymes containing a Rossmann fold, an Arg forms a cation-pi interaction with the adenine ring system (Cahn et al., 2017). Therefore, it is not unexpected that Arg and Lys were the most incorporated amino acid when switching from NAD to NADP, and most replaced ones when inverting the cofactor specificity to NAD (Schepens et al., 2000; Brinkmann-Chen et al., 2013).

Alanine has also been frequently used for both, as a target residue and a replacement for bidirectional coenzyme engineering (Figures 1E,F). In some cases, alanine has been used to remove a hydrogen bond and debilitate the interaction between the natural coenzyme and its binding site (Woodyer et al., 2003; Bubner et al., 2008; Zeng et al., 2009; Lerchner et al., 2016). In other studies, Ala was used to increase the flexibility and 
size of the coenzyme binding site for a better acceptance of NADP (Hoelsch et al., 2013). Among these lines, alanine has also been used to replace the third glycine of the NADH-binding motif GxGxxG, hampering the interactions occurring in the Rossman fold and facilitating the use of NADP (Dambe et al., 2006). Alanine was also applied for the switching from NADP to NAD, this was the case for an isocitrate dehydrogenase where a valine was mutated to alanine reducing the distance between an Asp and the 2'- and 3'- hydroxyls of the ribose (Rodríguez-Arnedo et al., 2005). When switching from NADP to NAD, alanine was used to replace larger and more acidic amino acids, such as aspartate or glutamate, to broaden the binding site and facilitate the union of NADP (Zheng et al., 2013). Moreover, alanine scanning has been used to study the relevance of some positions for coenzyme binding (Kamerbeek et al., 2004).

Serine has been targeted to change coenzyme specificity toward NAD, and incorporated in the other direction (Figures 1E,F). Ser usually interacts with the phosphate group of NADP stabilizing the coenzyme binding (Schepens et al., 2000; Ge et al., 2014). The short side chain of Ser makes it difficult for the $\mathrm{OH}$ groups of $\mathrm{NAD}$-adenine moiety to interact with this residue in the coenzyme binding site (Ge et al., 2014). Therefore, in several studies a serine has been replaced to switch from NADP to NAD usage (Medina et al., 2001; Khoury et al., 2009), by Asp (Bastian et al., 2011; Brinkmann-Chen et al., 2013) and Arg (Chen et al., 1995; Rodríguez-Arnedo et al., 2005) respectively.

\section{COMPUTATIONAL TOOLS AND ALGORITHMS FOR SWITCHING THE COENZYME PREFERENCE}

Recently, computational tools and algorithms have been applied to assist in the selection of "hot" positions for coenzyme engineering. Cui et al. (2015) proposed a computational approach that enhances the hydrogen-bond interaction between an enzyme and its coenzyme, using only the protein structure of the target protein. Using this strategy, they reversed the coenzyme specificity of a dehydrogenase from NADH to NADPH (Cui et al., 2015). Khoury et al. (2009) used a computational approach based on the iterative protein redesign and optimization algorithm (IPRO). With this algorithm they generated in silico mutations to improve binding of NADH to the target enzyme evidenced by improved interaction energies. Seven out of ten designed mutants showed a significant switch in coenzyme specificity toward the desired coenzyme and two showed dual coenzyme specificity (Khoury et al., 2009). Brinkmann-Chen et al. (2014) developed an algorithm to reverse the cofactor preference based on structural analysis of the enzymes.

Cahn et al. (2017) developed a web tool for switching coenzyme preference in a general approach, allowing for its application to any oxidoreductase. This structure-guided, semi rational strategy named SCR-SALAD (Coenzyme Specificity Reversal-Structural Analysis and Library Design) involves three steps: (i) analysis of enzyme structure to detect crucial residues determining coenzyme specificity, (ii) design of small degenerated codon libraries targeting the detected positions and, (iii) recovery of the catalytic efficiency which is usually lost during modification. Using this program, cofactor specificity was efficiently switched in four structurally diverse NADPdependent enzymes. Despite the fact, that the authors did not try to reverse the coenzyme specificity of NAD-dependent enzymes, comparison of previously published studies with CSR-SALAD showed, that the generated libraries contained all the beneficial mutations for reversing the specificity from NAD to NADP. Although the results obtained by using CSRSALAD are promising, this web tool has not proven useful in multistep electron transfer pathways (for instance mono- and dioxygenases) and does not consider natural evolution with insertions and deletions (Cahn et al., 2017).

\section{CONCLUSIONS}

Efforts on inverting the cofactor specificity of oxidoreductases have been made for practical reasons. The process has proven to be complex, even though a reversal of the preference is usually achieved, a loss of efficiency regularly appears as a side effect. Among the publications analyzed, oxidoreductases acting on $\mathrm{CH}-\mathrm{OH}$ groups of donors (EC 1.1) have been the most studied, with high rates of successful reversals, while oxidoreductases acting on paired donors with incorporation or reduction of molecular oxygen (EC 1.14) have led to poor efficiencies, most probably due to the decoupling of flavindependent monooxygenases present in this group. In all studies covered by this review, positions were selected rationally and site directed mutagenesis was the most common methodology to introduce the changes. Moreover, when the enzyme structure was available and applied, better results have been obtained. Loop engineering provided the best results, however it was used in only 5 specific cases. We believe that more studies should consider this technique in the future, specifically to have a more compelling statement regarding the favorable results. NADP depending enzymes usually present positively charged residues in their coenzyme union site in positions able to interact with the phosphate group of the adenosine ribose moiety or to establish hydrogen bonding with it. Contrarily, NAD-dependent enzymes possess positively charged residues. These residues are the most added or eliminated depending on the desired coenzyme specificity. Although early works on coenzyme engineering already used enzyme structures for mutational design, the availability of novel structures crystalized with the corresponding coenzyme will undoubtedly help in future rational cofactor engineering. Moreover, most recent works include new computational strategies, which make coenzyme specificity changes much simpler. The satisfactory results obtained by using computational tools and algorithms make us believe that their application will be widespread in coenzyme engineering. We expect that improvement of these strategies, and also novel tools, will become available in the near future.

Despite we did not cover the natural reaction of the engineered enzymes, we believe it would be interesting in future 
coenzyme engineering studies to give an insight of the relation between the natural reaction of the enzyme, the test reaction reported and the success of the switch.

\section{AUTHOR CONTRIBUTIONS}

All authors listed, have made substantial, direct and intellectual contribution to the work, and approved it for publication.

\section{REFERENCES}

Andreadeli, A., Platis, D., Tishkov, V., Popov, V., and Labrou, N. E. (2008). Structure-guided alteration of coenzyme specificity of formate dehydrogenase by saturation mutagenesis to enable efficient utilization of NADP+. FEBS J. 275, 3859-3869. doi: 10.1111/j.1742-4658.2008.06533.x

Ashida, H., Galkin, A., Kulakova, L., Sawa, Y., Nakajima, N., and Esaki, N. (2004). Conversion of cofactor specificities of alanine dehydrogenases by site-directed mutagenesis. J. Mol. Catal. B Enzym. 30, 173-176. doi: $10.1016 /$ j.molcatb.2004.04.008

Bae, B., Sullivan, R. P., Zhao, H., and Nair, S. K. (2010). Structure and engineering of l-arabinitol 4-dehydrogenase from Neurospora crassa. J. Mol. Biol. 402, 230-240. doi: 10.1016/j.jmb.2010.07.033

Baroni, S., Pandini, V., Vanoni, M. A., and Aliverti, A. (2012). A single tyrosine hydroxyl group almost entirely controls the NADPH Specificity of Plasmodium falciparum ferredoxin-NADP+ reductase. Biochemistry 51, 3819-3826. doi: 10.1021/bi300078p

Bastian, S., Liu, X., Meyerowitz, J. T., Snow, C. D., Chen, M. M., and Arnold, F. H. (2011). Engineered ketol-acid reductoisomerase and alcohol dehydrogenase enable anaerobic 2-methylpropan-1-ol production at theoretical yield in Escherichia coli. Metab. Eng. 13, 345-352. doi: 10.1016/j.ymben.2011.02.004

Beier, A., Bordewick, S., Genz, M., Schmidt, S., van den Bergh, T., Peters, C., et al. (2016). Switch in cofactor specificity of a Baeyer- villiger monooxygenase. ChemBioChem 17, 2312-2315. doi: 10.1002/cbic.201600484

Bernard, N., Johnsen, K., Holbrook, J. J., and Delcour, J. (1995). D175 discriminates between NADH and NADPH in the coenzyme binding site of Lactobacillus delbrueckii subsp. bulgaricus D-lactate dehydrogenase. Biochem. Biophys. Res. Commun. 208, 895-900. doi: 10.1006/bbrc.1995.1419

Bocanegra, J. A., Scrutton, N. S., and Perham, R. N. (1993). Creation of an NADP-dependent pyruvate dehydrogenase multienzyme complex by protein engineering. Biochemistry 32, 2737-2740. doi: 10.1021/bi00062a001

Bommareddy, R. R., Chen, Z., Rappert, S., and Zeng, A. (2014). A de novo NADPH generation pathway for improving lysine production of Corynebacterium glutamicum by rational design of the coenzyme specificity of glyceraldehyde 3-phosphate dehydrogenase. Metab. Eng. 25, 30-37. doi: 10.1016/j.ymben.2014.06.005

Brinkmann-Chen, S., Cahn, J. K. B., and Arnold, F. H. (2014). Uncovering rare NADH-preferring ketol-acid reductoisomerases. Metab. Eng. 26, 17-22. doi: 10.1016/j.ymben.2014.08.003

Brinkmann-Chen, S., Flock, T., Cahn, J. K., Snow, C. D., Brustad, E. M., McIntosh, J. A., et al. (2013). General approach to reversing ketol-acid reductoisomerase cofactor dependence from NADPH to NADH. Proc. Natl. Acad. Sci. U.S.A. 110, 10946-10951. doi: 10.1073/pnas.1306073110

Bubner, P., Klimacek, M., and Nidetzky, B. (2008). Structure-guided engineering of the coenzyme specificity of Pseudomonas fluorescens mannitol 2dehydrogenase to enable efficient utilization of $\mathrm{NAD}(\mathrm{H})$ and $\mathrm{NADP}(\mathrm{H})$. FEBS Lett. 582, 233-237. doi: 10.1016/j.febslet.2007.12.008

Cahn, J. K., Werlang, C. A., Baumschlager, A., Brinkmann-Chen, S., Mayo, S. L., and Arnold, F. H. (2017). A general tool for engineering the NAD/NADP cofactor preference of oxidoreductases. ACS Synth. Biol. 6, 326-333. doi: 10.1021/acssynbio.6b00188

Capone, M., Scanlon, D., Griffin, J., and Engel, P. C. (2011). Re-engineering the discrimination between the oxidized coenzymes NAD+ and NADP+ in clostridial glutamate dehydrogenase and a thorough reappraisal of the

\section{FUNDING}

Institute for Biological and Medical Engineering, Schools of Engineering, Medicine and Biological Sciences, Pontificia Universidad Católica de Chile.

\section{ACKNOWLEDGMENTS}

We would like to thank Dr. Lars Ratjen for helpful discussions.

coenzyme specificity of the wild-type enzyme. FEBS J. 278, 2460-2468. doi: 10.1111/j.1742-4658.2011.08172.x

Carrigan, J. B., and Engel, P. C. (2007). Probing the determinants of coenzyme specificity in Peptostreptococcus asaccharolyticus glutamate dehydrogenase by site-directed mutagenesis. FEBS J. 274, 5167-5174. doi: 10.1111/j.1742-4658.2007.06038.x

Carugo, O., and Argos, P. (1997). NADP-dependent enzymes. I: conserved stereochemistry of cofactor binding. Proteins Struct. Funct. Genet. 28, 10-20. doi: 10.1002/(SICI)1097-0134(199705)28:1<10::AID-PROT2>3.0.CO;2-N

Chen, R., Greer, A., and Dean, A. M. (1995). A highly active decarboxylating dehydrogenase with rationally inverted coenzyme specificity. Proc. Natl. Acad. Sci. U.S.A. 92, 11666-11670. doi: 10.1073/pnas.92.25.11666

Chen, R., Greer, A., and Dean, A. M. (1996). Redesigning secondary structure to invert coenzyme specificity in isopropylmalate dehydrogenase. Proc. Natl. Acad. Sci. U.S.A. 93, 12171-12176. doi: 10.1073/pnas.93.22.12171

Chen, Z., Tsigelny, I., Lee, W. R., Bakerd, M. E., and Chang, S. H. (1994). Adding a positive charge at residue 46 of Drosophila alcohol dehydrogenase increases cofactor specificity for NADP+. FEBS Lett. 356, 81-85. doi: 10.1016/0014-5793(94)01234-2

Clermont, S., Corbier, C., Mely, Y., Gerard, D., Wonacott, A., and Branlant, G. (1993). Determinants of coenzyme specificity in glyceraldehyde-3phosphate dehydrogenase: role of the acidic residue in the fingerprint region of the nucleotide binding fold. Biochemistry 32, 10178-10184. doi: 10.1021/bi00089a038

Cui, D., Zhang, L., Jiang, S., Yao, Z., Gao, B., Lin, J., et al. (2015). A computational strategy for altering an enzyme in its cofactor preference to $\mathrm{NAD}(\mathrm{H})$ and/or NADP(H). FEBS J. 282, 2339-2351. doi: 10.1111/febs.13282

Dambe, T. R., Kuhn, A. M., Brossette, T., Giffhorn, F., and Scheidig, A. J. (2006). Crystal structure of $\mathrm{NADP}(\mathrm{H})$-dependent 1,5-anhydro-D-fructose reductase from Sinorhizobium morelense at $2.2 \AA$ resolution: construction of a NADHaccepting mutant and its application in rare sugar synthesis. Biochemistry 45, 10030-10042. doi: 10.1021/bi052589q

Döhr, O., Paine, M. J., Friedberg, T., Roberts, G. C., and Wolf, C. R. (2001). Engineering of a functional human NADH-dependent cytochrome P450 system. Proc. Natl. Acad. Sci. U.S.A. 98, 81-86. doi: 10.1073/pnas.98.1.81

Dudek, H. M., Pazmiño, D. E. T., Rodríguez, C., de Gonzalo, G., Gotor, V., and Fraaije, M. W. (2010). Investigating the coenzyme specificity of phenylacetone monooxygenase from Thermobifida fusca. Appl. Microbiol. Biotechnol. 88, 1135-1143. doi: 10.1007/s00253-010-2769-y

Ehrensberger, A. H., Elling, R. A., and Wilson, D. K. (2006). Structure-guided engineering of xylitol dehydrogenase cosubstrate specificity. Structure 14, 567-575. doi: 10.1016/j.str.2005.11.016

Ehsani, M., Fernández, M. R., Biosca, J. A., and Dequin, S. (2009). Reversal of coenzyme specificity of 2,3-butanediol dehydrogenase from Saccharomyces cerevisae and in vivo functional analysis. Biotechnol. Bioeng. 104, 381-389. doi: 10.1002/bit.22391

Elmore, C. L., and Porter, T. D. (2002). Modification of the nucleotide cofactorbinding site of cytochrome P-450 reductase to enhance turnover with NADH in vivo. J. Biol. Chem. 277, 48960-48964. doi: 10.1074/jbc.M210173200

Eppink, M. H. M., Overkamp, K. M., Schreuder, H. A., Berkel, W. J. H., Van, and Roussel, H. M. (1999). Switch of coenzyme specificity of p -hydroxybenzoate hydroxylase. J. Mol. Biol. 292, 87-96. doi: 10.1006/jmbi.1999.3015

Fasan, R., Crook, N. C., Peters, M. W., Meinhold, P., Buelter, T., Landwehr, M., et al. (2011). Improved product-per-glucose yields in P450-dependent propane 
biotransformations using engineered Escherichia coli. Biotechnol. Bioeng. 108, 500-510. doi: 10.1002/bit.22984

Feeney, R., Clarke, A. R., and Holbrook, J. J. (1990). A single amino acid substitution in lactate dehydrogenase improves the catalytic efficiency with an alternative coenzyme. Biochem. Biophys. Res. Commun. 166, 667-672. doi: 10.1016/0006-291X(90)90861-G

Fernandes, S., Tuohy, M. G., and Murray, P. G. (2009). Xylose reductase from the thermophilic fungus Talaromyces emersonii: cloning and heterologous expression of the native gene (Texr) and a double mutant (TexrK271R+N273D) with altered coenzyme specificity. J. Biosci. 34, 881-890. doi: 10.1007/s12038-009-0102-7

Friesen, J. A., Lawrence, C. M., Stauffacher, C. V., and Rodwell, V. W. (1996). Structural determinants of nucleotide coenzyme specificity in the distinctive dinucleotide binding fold of HMG-CoA reductase from Pseudomonas mevalonii. Biochemistry 35, 11945-11950. doi: 10.1021/bi9609937

Galkin, A., Kulakova, L., Ohshima, T., Esaki, N., and Soda, K. (1997). Construction of a new leucine dehydrogenase with preferred specificity for NADP+ by sitedirected mutagenesis of the strictly NAD+ -specific enzyme. Protein Eng. 10, 687-690. doi: 10.1093/protein/10.6.687

Gand, M., Thöle, C., Müller, H., Brundiek, H., Bashiri, G., and Höhne, M. (2016). A NADH-accepting imine reductase variant: immobilization and cofactor regeneration by oxidative deamination. J. Biotechnol. 230, 11-18. doi: 10.1016/j.jbiotec.2016.05.006

Ge, Y. D., Song, P., Cao, Z. Y., Wang, P., and Zhu, G. P. (2014). Alteration of coenzyme specificity of malate dehydrogenase from Streptomyces coelicolor A3(2) by site-directed mutagenesis. Genet. Mol. Res. 13, 5758-5766. doi: 10.4238/2014.July.29.3

Girvan, H. M., Dunford, A. J., Neeli, R., Ekanem, I. S., Waltham, T. N., Joyce, M. G., et al. (2011). Flavocytochrome P450 BM3 mutant W1046A is a NADH-dependent fatty acid hydroxylase : implications for the mechanism of electron transfer in the P450 BM3 dimer. Arch. Biochem. Biophys. 507, 75-85. doi: 10.1016/j.abb.2010.09.014

Gul-karaguler, N., Sessions, R. B., Clarke, A. R., and Holbrook, J. J. (2001). A single mutation in the NAD-specific formate dehydrogenase from Candida methylica allows the enzyme to use NADP. Biotechnol. Lett. 23, 283-287. doi: 10.1023/A:1005610414179

Hanukoglu, I., and Gutfinger, T. (1989). cDNA sequence of adrenodoxin reductase. Eur. J. Biochem. 180, 479-484. doi: 10.1111/j.1432-1033.1989. tb14671.x

Hatrongjit, R., and Packdibamrung, K. (2010). A novel NADP+-dependent formate dehydrogenase from Burkholderia stabilis 15516: screening, purification and characterization. Enzyme Microb. Technol. 46, 557-561. doi: 10.1016/j.enzmictec.2010.03.002

Hoelsch, K., Sührer, I., Heusel, M., and Weuster-Botz, D. (2013). Engineering of formate dehydrogenase: synergistic effect of mutations affecting cofactor specificity and chemical stability. Appl. Microbiol. Biotechnol. 97, 2473-2481. doi: 10.1007/s00253-012-4142-9

Holmberg, N., Ryde, U., and Bülow, L. (1999). Redesign of the coenzyme specificity in L-lactate dehydrogenase from Bacillus stearothermophilus using site-directed mutagenesis and media engineering. Protein Eng. 12, 851-856. doi: $10.1093 /$ protein/12.10.851

Hong, S. H., Ngo, H. P., Nam, H. K., Kim, K. R., Kang, L. W., and Oh, D. K., (2016). Alternative biotransformation of retinal to retinoic acid or retinol by an aldehyde dehydrogenase from Bacillus cereus. Appl. Environ. Microbiol. 82, 3940-3946. doi: 10.1128/AEM.00848-16

Hsieh, J. Y., Liu, G. Y., Chang, G. G., and Hung, H. C. (2006). Determinants of the dual cofactor specificity and substrate cooperativity of the human mitochondrial NAD(P)-dependent Malic enzyme. J. Biol. Chem. 281, 23237-23245. doi: 10.1074/jbc.M603451200

Huang, Y. W., Pineau, I., Chang, H. J., Azzi, A., Bellemare, V., Laberge, S., et al. (2001). Critical residues for the specificity of cofactors and substrates in human estrogenic $17 \beta$-hydroxysteroid dehydrogenase 1: variants designed from the three-dimensional structure of the enzyme. Mol. Endocrinol. 15, 2010-2020. doi: 10.1210/mend.15.11.0730

Hurley, J. H., Chen, R., and Dean, A. M. (1996). Determinants of cofactor specificity in isocitrate dehydrogenase: structure of an engineered NADP+ $\rightarrow \quad$ NAD+ specificity-reversal mutant. Biochemistry 35, 5670-5678. doi: $10.1021 /$ bi $953001 \mathrm{q}$
Jensen, C. N., Ali, S. T., Allen, M. J., and Grogan, G. (2013). Mutations of an $\mathrm{NAD}(\mathrm{P}) \mathrm{H}$-dependent flavoprotein monooxygenase that influence cofactor promiscuity and enantioselectivity. FEBS Open Bio 3, 473-478. doi: 10.1016/j.fob.2013.09.008

Jensen, C. N., Ali, S. T., Allen, M. J., and Grogan, G. (2014). Exploring nicotinamide cofactor promiscuity in $\mathrm{NAD}(\mathrm{P}) \mathrm{H}$-dependent flavin containing monooxygenases (FMOs) using natural variation within the phosphate binding loop. Structure and activity of FMOs from Cellvibrio sp. BR and Pseudomonas stutzeri NF13. J. Mol. Catal. Enzym. 109, 191-198. doi: 10.1016/j.molcatb.2014.08.019

Kamerbeek, N. M., Fraaije, M. W., and Janssen, D. B. (2004). Identifying determinants of NADPH specificity in Baeyer-Villiger monooxygenases. Eur. J. Biochem. 271, 2107-2116. doi: 10.1111/j.1432-1033.2004.04126.x

Katzberg, M., Skorupa-Parachin, N., Gorwa-Grauslund, M. F., and Bertau, M. (2010). Engineering cofactor preference of ketone reducing biocatalysts: a mutagenesis study on a $\gamma$-diketone reductase from the yeast Saccharomyces cerevisiae serving as an example. Int. J. Mol. Sci. 11, 1735-1758. doi: $10.3390 /$ ijms 11041735

Khoury, G. A., Fazelinia, H., Chin, J. W., Pantazes, R. J., Cirino, P. C., and Maranas, C. D. (2009). Computational design of Candida boidinii xylose reductase for altered cofactor specificity. Protein Sci. 18, 2125-2138. doi: 10.1002/pro.227

Kim, B., Sullivan, R. P., and Zhao, H. (2010). Cloning, characterization, and engineering of fungal L-arabinitol dehydrogenases. Appl. Microbiol. Biotechnol. 87, 1407-1414. doi: 10.1007/s00253-010-2593-4

Knaus, T., Paul, C. E., Levy, C. W., de Vries, S., Mutti, F. G., Hollmann, F., et al. (2016). Better than nature: nicotinamide biomimetics that outperform natural coenzymes. J. Am. Chem. Soc. 138, 1033-1039. doi: 10.1021/jacs. $5 \mathrm{~b} 12252$

Kristan, K., Stojan, J., Adamski, J., and Lanisnik RiZner, T. (2007). Rational design of novel mutants of fungal $17 \beta$-hydroxysteroid dehydrogenase. J. Biotechnol. 129, 123-130. doi: 10.1016/j.jbiotec.2006.11.025

Kumar, H., Nguyen, Q. T., Binda, C., Mattevi, A., and Fraaije, M. W. (2017). Isolation and characterization of a thermostable F420: NADPH oxidoreductase from Thermobifida fusca. J. Biol. Chem. 292, 10123-10130. doi: 10.1074/jbc.M117.787754

Lerchner, A., Jarasch, A., and Skerra, A. (2016). Engineering of alanine dehydrogenase from Bacillus subtilis for novel cofactor specificity. Biotechnol. Appl. Biochem. 63, 616-624. doi: 10.1002/bab.1414

Liang, L., Zhang, J., and Lin, Z. (2007). Altering coenzyme specificity of Pichia stipitis xylose reductase by the semi-rational approach CASTing. Microb. Cell Fact. 6, 1-11. doi: 10.1186/1475-2859-6-36

Ma, C., Zhang, L., Dai, J., and Xiu, Z. (2010). Relaxing the coenzyme specificity of 1,3-propanediol oxidoreductase from Klebsiella pneumoniae by rational design. J. Biotechnol. 146, 173-178. doi: 10.1016/j.jbiotec.2010.02.005

Maddock, D. J., Patrick, W. M., and Gerth, M. L. (2015). Substitutions at the cofactor phosphate-binding site of a clostridial alcohol dehydrogenase lead to unexpected changes in substrate specificity. Protein Eng. Des. Sel. 28, 251-258. doi: 10.1093/protein/gzv028

Marohnic, C. C., Bewley, M. C., and Barber, M. J. (2003). Engineering and characterization of a NADPH-utilizing cytochrome b5 reductase. Biochemistry 42, 11170-11182. doi: 10.1021/bi034819b

Maurer, S. C., Kühnel, K., Kaysser, L. A., Eiben, S., Schmid, R. D., and Urlacher, V. B. (2005). Catalytic hydroxylation in biphasic systems using CYP102A1 mutants. Adv. Synth. Catal. 347, 1090-1098. doi: 10.1002/adsc.2005 05044

May, S. W. (1999). Applications of oxidoreductases. Curr. Opin. Biotechnol. 10, 370-375. doi: 10.1016/S0958-1669(99)80067-6

May, S. W., and Padgette, S. R. (1983). Oxidoreductase enzymes in biotechnology: current status and future potential. Nat. Biotechnol. 1, 677-686. doi: 10.1038/nbt1083-677

Medina, M., Luquita, A., Tejero, J., Hermoso, J., Mayoral, T., Sanz-Aparicio, J., et al. (2001). Probing the determinants of coenzyme specificity in ferredoxin-NADP+ reductase by site-directed mutagenesis. J. Biol. Chem. 276, 11902-11912. doi: 10.1074/jbc.M009287200

Miller, S. P., Lunzer, M., and Dean, A. M. (2006). Direct demonstration of an adaptive constraint. Science 314, 458-461. doi: 10.1126/science.1133479

Nakanishi, M., Matsuura, K., Kaibe, H., Tanaka, N., Mitsui, Y., and Hara, A. (1997). Switch of coenzyme specificity of mouse lung carbonyl reductase by 
substitution of threonine 38 with aspartic acid. J. Biol. Chem. 272, 2218-2222. doi: $10.1074 /$ jbc.272.4.2218

Nishiyama, M., Birktoft, J. J., and Beppu, T. (1993). Alteration of coenzyme specificity of malate dehydrogenase from Thermus flavus by site-directed mutagenesis. J. Biol. Chem. 268, 4656-4660.

Paladini, D. H., Musumeci, M. A., Carrillo, N., and Ceccarelli, E. A. (2009). Induced fit and equilibrium dynamics for high catalytic efficiency in ferredoxinNADP(H) reductases. Biochemistry 48, 5760-5768. doi: 10.1021/bi9004232

Paul, C. E., Arends, I. W. C. E., and Hollmann, F. (2014). Is simpler better? Synthetic nicotinamide cofactor analogues for redox chemistry. ACS Catal. 4, 788-797. doi: 10.1021/cs4011056

Petschacher, B., Leitgeb, S., Kavanagh, K. L., Wilson, D. K., and Nidetzky, B. (2005). The coenzyme specificity of Candida tenuis xylose reductase (AKR2B5) explored by site-directed mutagenesis and X-ray crystallography. Biochem. J. 83, 75-83. doi: 10.1042/BJ20040363

Petschacher, B., Staunig, N., Müller, M., Schürmann, M., Mink, D., De Wildeman, S., et al. (2014). Cofactor specificity engineering of streptococcus mutans $\mathrm{NADH}$ oxidase 2 for $\mathrm{NAD}(\mathrm{P})+$ regeneration in biocatalytic oxidations. Comput. Struct. Biotechnol. J. 9:e201402005. doi: 10.5936/csbj.201402005

Pick, A., Ott, W., Howe, T., Schmid, J., and Sieber, V. (2014). Improving the NADH-cofactor specificity of the highly active AdhZ3 and AdhZ2 from Escherichia coli K-12. J. Biotechnol. 189, 157-165. doi: 10.1016/j.jbiotec.2014.06.015

Pire, C., Esclapez, J., Díaz, S., Ferrer, J., and Bonete, M. J. (2009). Alteration of coenzyme specificity in halophilic $\mathrm{NAD}(\mathrm{P})+$ glucose dehydrogenase by site-directed mutagenesis. J. Mol. Catal. B Enzym. 59, 261-265. doi: 10.1016/j.molcatb.2008.07.013

Rane, M. J., and Calvo, K. C. (1997). Reversal of the nucleotide specificity of ketol acid reductoisomerase by site-directed mutagenesis identifies the NADPH binding site. Arch. Biochem. Biophys. 338, 83-89. doi: 10.1006/abbi.199 6.9802

Rodríguez-Arnedo, A., Camacho, M., Llorca, F., and Bonete, M. J. (2005). Complete reversal of coenzyme specificity of isocitrate dehydrogenase from Haloferax volcanii. Protein J. 24, 259-266. doi: 10.1007/s10930-005-6746-8

Rosell, A., Valencia, E., Ochoa, W. F., Fita, I., Parés, X., and Farrés, J. (2003). Complete reversal of coenzyme specificity by concerted mutation of three consecutive residues in alcohol dehydrogenase. J. Biol. Chem. 278, 40573-40580. doi: 10.1074/jbc.M307384200

Schepens, I., Johansson, K., Decottignies, P., Gillibert, M., Hirasawa, M., Knaff, D. B., et al. (2000). Inhibition of the thioredoxin-dependent activation of the NADP-malate dehydrogenase and cofactor specificity. J. Biol. Chem. 275, 20996-21001. doi: 10.1074/jbc.M002066200

Scrutton, N. S., Berry, A., and Perham, R. N. (1990). Redesign of the coenzyme specificity of a dehydrogenase by protein engineering. Nature 343, 38-43. doi: $10.1038 / 343038 \mathrm{a} 0$

Serov, A. E., Popova, A. S., Fedorchuk, V. V., and Tishkov, V. I. (2002). Engineering of coenzyme specificity of formate dehydrogenase from Saccharomyces cerevisiae. Biochem. J. 367, 841-847. doi: 10.1042/bj20020379

Sharkey, M. A., Gori, A., Capone, M., and Engel, P. C. (2012). Reversal of the extreme coenzyme selectivity of Clostridium symbiosum glutamate dehydrogenase. FEBS J. 279, 3003-3009. doi: 10.1111/j.1742-4658.2012. 08681.x

Shiraishi, N., Croy, C., Kaur, J., and Campbell, W. H. (1998). Engineering of pyridine nucleotide specificity of nitrate reductase: mutagenesis of recombinant cytochrome b reductase fragment of Neurospora crassa. Arch. Biochem. Biophys. 358, 104-115. doi: 10.1006/abbi.1998.0827

Solanki, K., Abdallah, W., and Banta, S. (2016). Extreme makeover: engineering the activity of a thermostable alcohol dehydrogenase (AdhD) from Pyrococcus furiosus. Biotechnol. J. 11, 1483-1497. doi: 10.1002/biot.201600152
Solanki, K., Abdallah, W., and Banta, S. (2017). Engineering the cofactor specificity of an alcohol dehydrogenase via single mutations or insertions distal to the $2^{\prime}$-phosphate group of $\mathrm{NADP}(\mathrm{H})$. Biotechnol. Bioeng. 30, 373-380. doi: 10.1093/protein/gzx009

Stiti, N., Podgórska, K., and Bartels, D. (2014). Aldehyde dehydrogenase enzyme ALDH3H1 from Arabidopsis thaliana: identification of amino acid residues critical for cofactor specificity. Biochim. Biophys. Acta 1844, 681-693. doi: 10.1016/j.bbapap.2014.01.008

Takase, R., Mikami, B., Kawai, S., Murata, K., and Hashimoto, W. (2014). Structure-based conversion of the coenzyme requirement of a short-chain dehydrogenase/reductase involved in bacterial alginate metabolism. J. Biol. Chem. 289, 33198-33214. doi: 10.1074/jbc.M114.585661

Torres Pazmiño, D. E., Winkler, M., Glieder, A., and Fraaije, M. W. (2010). Monooxygenases as biocatalysts: classification, mechanistic aspects and biotechnological applications. J. Biotechnol. 146, 9-24. doi: 10.1016/j.jbiotec.2010.01.021

Watanabe, S., Kodaki, T., and Makino, K. (2005). Complete reversal of coenzyme specificity of xylitol dehydrogenase and increase of thermostability by the introduction of structural zinc. J. Biol. Chem. 280, 10340-10349. doi: 10.1074/jbc.M409443200

Woodyer, R., van der Donk, W. A., Zhao, H., June, R. V., Re, V., Recei, M., et al. (2003). Relaxing the nicotinamide cofactor specificity of phosphite dehydrogenase by rational design. Biochemistry 42, 11604-11614. doi: 10.1021/bi035018b

Wu, W., Zhu, D., and Hua, L. (2009). Enzymatic site-saturation mutagenesis of formate dehydrogenase from Candida bodinii creating effective NADP+-dependent FDH enzymes. J. Mol. Catal. B Enzym. 61, 157-161. doi: 10.1016/j.molcatb.2009.06.005

$\mathrm{Xu}, \mathrm{F}$. (2005). Applications of oxidoreductases: recent progress. Ind. Biotechnol. 1, 38-50. doi: 10.1089/ind.2005.1.38

Yaoi, T., Miyazaki, K., Oshima, T., Komukai, Y., and Go, M. (1996). Conversion of the coenzyme specificity of isocitrate dehydrogenase by module replacement. J. Biochem. 119, 1014-1018. doi: 10.1093/oxfordjournals.jbchem.a021316

Zeng, Q. K., Du, H. L., Wang, J. F., Wei, D. Q., Wang, X. N., Li, Y. X., et al. (2009). Reversal of coenzyme specificity and improvement of catalytic efficiency of Pichia stipitis xylose reductase by rational site-directed mutagenesis. Biotechnol. Lett. 31, 1025-1029. doi: 10.1007/s10529-009-9980-x

Zhang, L., Ahvazi, B., Szittner, R., Vrielink, A., and Meighen, E. (1999). Change of nucleotide specificity and enhancement of catalytic efficiency in single point mutants of Vibrio harveyi aldehyde dehydrogenase. Biochemistry 3, 11440-11447. doi: 10.1021/bi991101g

Zhang, R., Xu, Y., Sun, Y., Zhang, W., and Xiao, R. (2009). Ser67Asp and His68Asp substitutions in Candida parapsilosis carbonyl reductase alter the coenzyme specificity and enantioselectivity of ketone reduction. Appl. Environ. Microbiol. 75, 2176-2183. doi: 10.1128/AEM.02519-08

Zheng, H., Bertwistle, D., Sanders, D. A., and Palmer, D. R. (2013). Converting NAD-specific inositol dehydrogenase to an efficient NADP-selective catalyst, with a surprising twist. Biochemistry 52, 5876-5883. doi: 10.1021/bi400821s

Conflict of Interest Statement: The authors declare that the research was conducted in the absence of any commercial or financial relationships that could be construed as a potential conflict of interest.

Copyright (c) 2018 Chánique and Parra. This is an open-access article distributed under the terms of the Creative Commons Attribution License (CC BY). The use, distribution or reproduction in other forums is permitted, provided the original author(s) and the copyright owner are credited and that the original publication in this journal is cited, in accordance with accepted academic practice. No use, distribution or reproduction is permitted which does not comply with these terms. 